\title{
Influences of environmental context on the recency effect in free recall
}

\author{
TAKEO ISARIDA \\ Shizuoka University, Hamamatsu, Japan \\ and \\ TOSHIKO K. ISARIDA \\ Shizuoka Prefectural University, Shizuoka, Japan
}

\begin{abstract}
A total of 208 undergraduate participants incidentally encoded a list of seven pairs of familiar words in two experiments. A 30-sec calculation task was imposed before and after each pair was encoded. Participants received a free recall test $24 \mathrm{~h}$ (Experiment 1) or $10 \mathrm{~min}$ (Experiment 2) after the encoding session, under conditions in which the original environmental context was reinstated or not. The environmental context was manipulated in terms of the combination of the physical features of the room, the subsidiary task conducted, the experimenter (Experiment 1), or background music (Experiment 2). A recency effect appeared when the original environmental context was reinstated in both experiments, even though the IPI/RI ratio was too small to produce recency effects according to the ratio rule. The results imply that the environmental context should be taken into account for the recency effect.
\end{abstract}

In the present study, we focus on the production mechanisms of recency effects. The term recency effect refers to the phenomenon that the last few items on a well-ordered list tend to be recalled better than the items in the middle of the list. The recency effect was once regarded as evidence for a distinction between short-term and long-term memory systems (see, e.g., Craik, 1970; Glanzer \& Cunitz, 1966). However, some attempts to explain recency effects by assuming distinctions between short-term and long-term memory have not succeeded (e.g., Koppenaal \& Glanzer, 1990; Neath, 1993; Thaper \& Greene, 1993). Currently, a unitary memory system is more generally accepted as an explanation of recency effects (e.g., Bjork, 2001; Crowder, 1993; Glenberg, Bradley, Kraus, \& Renzaglia, 1983; Glenberg et al., 1980; Tan \& Ward, 2000). Yet recently, a distinction between short-term and long-term recency effects has again been proposed (Davelaar, Goshen-Gottstein, Ashkenazi, Haarmann, \& Usher, 2005). Thus, the controversy between the unitary memory and the dichotomy theories may arise once more. Nonetheless, unitary memory theories can still explain the recency effect well, and the longterm recency effect in particular.

Various unitary memory theories or hypotheses explain the recency effect. These theories do so with recourse to

The authors thank M. G. Sheftall for his comments on an earlier version of this article. Portions of this research were reported at the 57th Annual Meeting of the Japanese Psychological Association, Tokorozawa, Japan and at the 67th Annual Meeting of the Japanese Psychological Association, Tokyo. Correspondence should be addressed to T. Isarida, Faculty of Informatics, Shizuoka University, 3-5-1 Johoku, Hamamatsu, 432-8011 Japan (e-mail: isarida@inf.shizuoka.ac.jp).

Note-This article was accepted by the previous editorial team, when Colin M. MacLeod was Editor. different principles, such as temporal distinctiveness (e.g., Crowder, 1993), contextual retrieval (e.g., Glenberg et al., 1983; Glenberg et al., 1980), and priming (e.g., Baddeley \& Hitch, 1993). However, they unanimously accept one influential empirical finding: the ratio rule (e.g., Crowder, 1976; Glenberg et al., 1983; Glenberg et al., 1980; Neath, 1993). This rule refers to the finding that the slope of the recency effect is determined by the ratio of the interpresentation interval (IPI) to the retention interval (RI). The ratio rule can be applicable to recency effects in a large number of free recall and continuous distractor studies of intentional or incidental learning (e.g., Bjork, 2001; Crowder, 1993; Glenberg, 1984, 1987; Glenberg et al.,1983; Glenberg et al.,1980; Glenberg \& Swanson, 1986; Neath \& Crowder, 1990; Tan \& Ward, 2000), and also to the size of forgetting curves in the Brown-Peterson paradigm and to the size of the primacy effect in free recall (Crowder, 1976; Tan \& Ward, 2000).

As unitary memory theorists, we accept the notion that the positional superiority of the recency portion to the middle portion of the list produces the recency effect. The positional superiority of the recency portion should be due to the end-of-the-list uniqueness, whether explained by temporal distinctiveness (e.g., Crowder, 1993), contextual cues (e.g., Glenberg et al., 1983; Glenberg et al., 1980), or priming (e.g., Baddeley \& Hitch, 1993). Because the end of the list is unique only within the specific list, the positional superiority of the recency portion may be revealed within the limits of the list-learning context. If this is the case, we would predict that the recency effect would appear within the list-learning context and disappear out of the context.

To test this prediction, in the present experiments we observed and compared recency effects within and out of the context present throughout the list-learning event. A 
continuous distractor paradigm with a nearly zero IPI/RI ratio was used. According to the ratio rule, there should be no recency effect in this condition. The list-learning context was reinstated in the same-context condition, but not in the different-context condition. The present experimental session consisted of one list-learning event in order to match the environmental context with the listlearning context, and to prevent environmental-context cue overload. The finding of a significant recency effect in the same-context condition but not in the differentcontext condition would confirm our present prediction. In contrast, a finding of no recency effect in either the same-context or the different-context condition would confirm the ratio rule.

Theoretically, the recency effect is one of the episodic memory phenomena influenced by the context present at encoding. Empirically, it has been demonstrated that memory performance is influenced by the reinstatement of the original environmental context as well as the RI (e.g., Smith, 1988; Smith \& Vela, 2001). Moreover, the reinstatement of the original environmental context has been shown to influence whether or not episodic memory phenomena appear (Isarida, 1992, 2005; Isarida \& Morii, 1986). Isarida and his colleague have found that the study time effect (Isarida, 2005), the rehearsal effect (Isarida, 1992), and the spacing effect (Isarida \& Morii, 1986) in free recall appear when the original environmental context is reinstated at the time of testing, whereas when the context is not reinstated they are eliminated (Isarida, 2005; Isarida \& Morii, 1986) or markedly diminished (Isarida, 1992, 2005). As such, the recency effect may be influenced by the contextual reinstatement.

In the present experiments, we manipulated three contextual elements to obtain more reliable environmental context effects. The three were the external physical environment during an experimental session, the subsidiary task performed with the encoding task, and the experimenter or the background music. The combined manipulation of place and experimenter has been found to produce more reliable context effects than simple place manipulation (Smith \& Vela, 2001). The combined manipulation of place and subsidiary task also produced a significant context effect, even if place alone did not produce the effect (Isarida \& Isarida, 2004). Although other elements than these three may aid reinstatement of the episode, they were not included in the present manipulation, because they were difficult to coordinate with the present manipulations. The elements not included were mood or internal states (e.g., Blaney, 1986; Eich, 1980), posture (e.g., Rand \& Wapner, 1967), various visual features of a computer screen for item presentation (e.g., Murnane \& Phelps, 1993), and so forth.

\section{EXPERIMENT 1}

In Experiment 1, we examined whether reinstatement of the environmental context present at encoding would produce a recency effect in a condition where no recency effect would be predicted according to the ratio rule. In this experiment, we used a 30 -sec IPI and a $24-\mathrm{h}$ RI, so that the IPI/RI ratio was nearly zero. If the recency effect is determined exclusively by the IPI/RI ratio, no recency effect should appear regardless of the reinstatement of the environmental context present at encoding. In contrast, if contextual reinstatement produces a significant recency effect despite a nearly zero IPI/RI ratio, then the generality of the ratio rule should be reconsidered.

\section{Method}

Design. A $2 \times 2$ mixed factorial design was used. Serial position (1-7) was the within-subjects factor. Context (same context, SC; different context, DC) was the between-subjects factor.

Participants. The participants were 104 undergraduates enrolled in an introductory psychology course at Shizuoka University, Shizuoka, Japan. They received extra course credit for participating. They were randomly assigned to the SC or DC condition, so that there were 52 participants in each condition.

Materials. A to-be-remembered list consisted of 14 unrelated Japanese two-kanji-character words whose imagery values and concreteness values were both more than 5.00 (Ogawa \& Inamura, 1974).

Context. All participants came individually for two 10-min sessions, an encoding session and a test session, separated by a 24-h retention interval. SC participants received a free recall test in the same context as that for the encoding session, whereas DC participants received it in a different context from that for the encoding session.

A combination of three contextual elements (place, experimenter, and task) was systematically varied. SC participants attended the test session in the same place as the encoding session, and received instructions from the same experimenter. In addition, before testing, SC participants engaged in the same calculation task that they had performed before and after encoding each pair of words. DC participants attended a different place for the test session than for the encoding session, the experimenter who instructed them was different for the two sessions, and no task was imposed before testing.

For the place element, two places (Place A and B) were selected to be as perceptually distinct as possible, each differing in size, illumination, and objects and apparatus. Place A was a dimly lit $175 \times$ $150 \mathrm{~cm}$ corner of a room, surrounded by two beige walls and two light blue partitioning curtains. In Place A, there was a 15-in. computer screen, a keyboard, a small table, and a chair. An experimenter instructed the participant from behind the participant's back and was then concealed behind the curtains during the experimental session. Place B was a brightly lit $375 \times 570 \mathrm{~cm}$ room. A large bookshelf covered one wall, three large cabinets stood along another wall, and a large window opening outside was on the third wall. In Place B, there was a notebook computer with a 10-in. computer screen and a keyboard. In Place B, the experimenter and the participant sat facing each other across a $180 \times 90 \mathrm{~cm}$ table throughout the session. Places A and B were on the same floor of the same building. Half of the SC participants were run in Place A for both encoding and test sessions, and the others were run in Place B. Half of the DC participants had the encoding session in Place A and were tested in Place B, and vice versa for the other half.

For the task element, the participants engaged in a 30-sec calculation task before and after encoding each pair of words. The participants were presented a three-term addition problem, one problem at a time, on a computer screen, and they were required to press the numeric key corresponding to the first digit of the sum as fast and correctly as they could. Feedback consisted of a "peep" tone for each correct response, and a buzzer for each incorrect response. Immediately after the feedback, the next problem was presented.

For the experimenter element, either the male teacher who lectured in a course that the participants attended (Experimenter A) or a female undergraduate who was not acquainted with the participants (Experimenter B) served as the experimenter. Half of the SC participants were instructed by Experimenter A and the others 


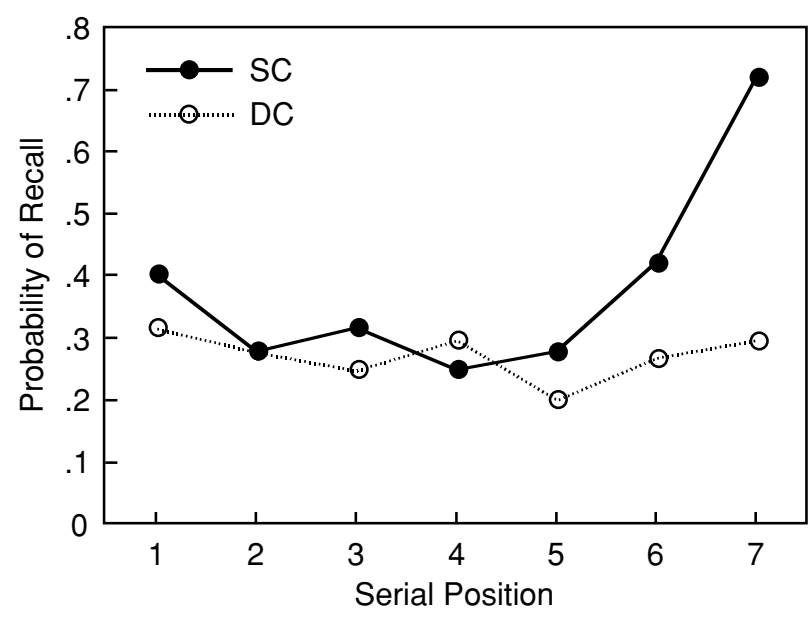

Figure 1. Serial position curves for same-context (SC) and different-context (DC) conditions in Experiment 1. Interpresentation interval $=30 \mathrm{sec}$; retention interval $=24 \mathrm{~h}$.

by Experimenter B at both the encoding and test sessions. In the alternate condition, half of the DC participants were instructed by Experimenter A at the encoding session and by Experimenter B at the test session, and vice versa for the other half.

Procedure. Except for the differences in the room and the experimenter, the procedure at the encoding session was identical for all participants. Each participant came individually to the teacher's room and was then escorted by Experimenter A or B to Place A or B. Following the instruction, the participant was presented seven pairs of words one pair at a time on a computer screen at a rate of $8 \mathrm{sec}$ per pair. The participant was required to generate a word association for the currently presented pair within $8 \mathrm{sec}$. They were not informed that they would be required to recall the words at a later session. The assignment of words to pairs and the presentation order of the pairs were randomized across participants. Every pair presentation was preceded and followed by a 30 -sec calculation task. The participant engaged in the calculation task eight times. Twenty-four hours after the encoding session, the participants received a 1-min oral free recall test in the SC or DC condition. After the recall test, an introspective report was made. Both the oral responses in recall and the introspective report were tape recorded. At the end of the experimental sessions, the participants were debriefed.

\section{Results}

The data were scored and analyzed for both words from each pair. Figure 1 shows the probability of recall of individual words as a function of context and serial position. A $2 \times 7$ (context $\times$ serial position) ANOVA was computed. The main effects of context $[F(1,102)=8.62$, $\left.M S_{\mathrm{e}}=0.72, p<.01\right]$ and serial position $[F(6,612)=$ $\left.7.15, M S_{\mathrm{e}}=0.67, p<.001\right]$ were significant, and the interaction of these factors was also significant $[F(6,612)=$ 2.22, $\left.M S_{\mathrm{e}}=0.67, p<.05\right]$. The simple context effects were analyzed for Serial Positions 1-7, because the interaction between serial position and context was significant. The context effect was not significant for Serial Positions $1-5$ ( $F \mathrm{~S}<1$ for all), was marginally significant for Serial Position $6[F(1,714)=2.78, p<.10]$, and was significant for Serial Position $7[F(1,714)=11.11, p<.001]$.

Figure 2 shows serial position curves for Output Positions 1-5 (cf. Howard \& Kahana, 1999) for SC (top panel) and DC (bottom panel) conditions in Experiment 1. At later output positions, there is insufficient data to plot reliable serial position curves. The SC serial position curve in Figure 2 is characterized mainly by the first two output positions. In contrast, the DC condition shows a large primacy effect for the first response but this primacy does not characterize the DC serial position curve in Figure 2. The other output positions showed no distinctive features.

Figure 3 shows the conditional response probability (cf. Howard \& Kahana, 1999; Kahana, 1996), which was modified for pair presentation. The lag zero refers to the present response and the preceding response belonging to the same pair. The SC and DC curves show an almost identical pattern, which consists of a pronounced peak at lag zero and low plains at both sides of the peak.

\section{Discussion}

The results of Experiment 1 show that reinstatement of the environmental context present at encoding can produce a recency effect even if the IPI/RI ratio is too low to produce it according to the ratio rule. The recall probability in the $\mathrm{SC}$ condition showed a clear recency effect, whereas there was no recency effect in the DC condition. This finding is
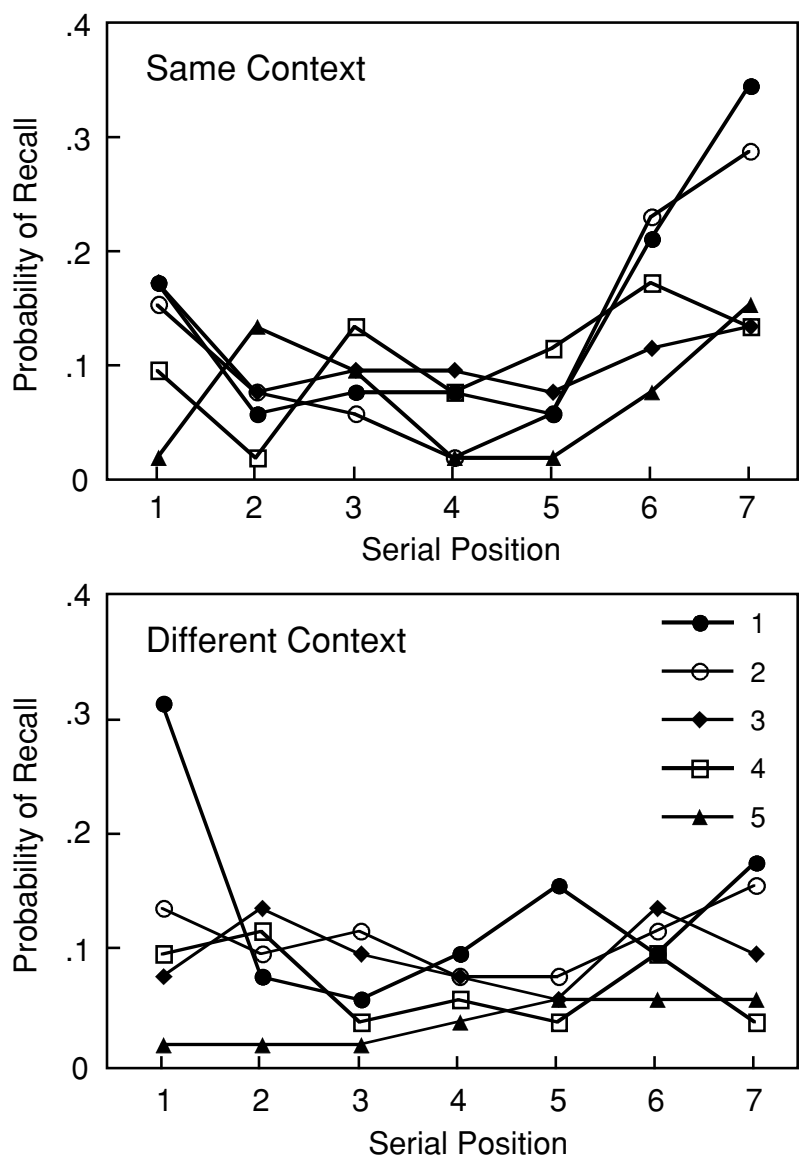

Figure 2. Serial position curves at Output Positions 1-5 for same-context (top panel) and different-context (bottom panel) conditions in Experiment 1. At later output positions, there is insufficient data to plot reliable serial position curves. 


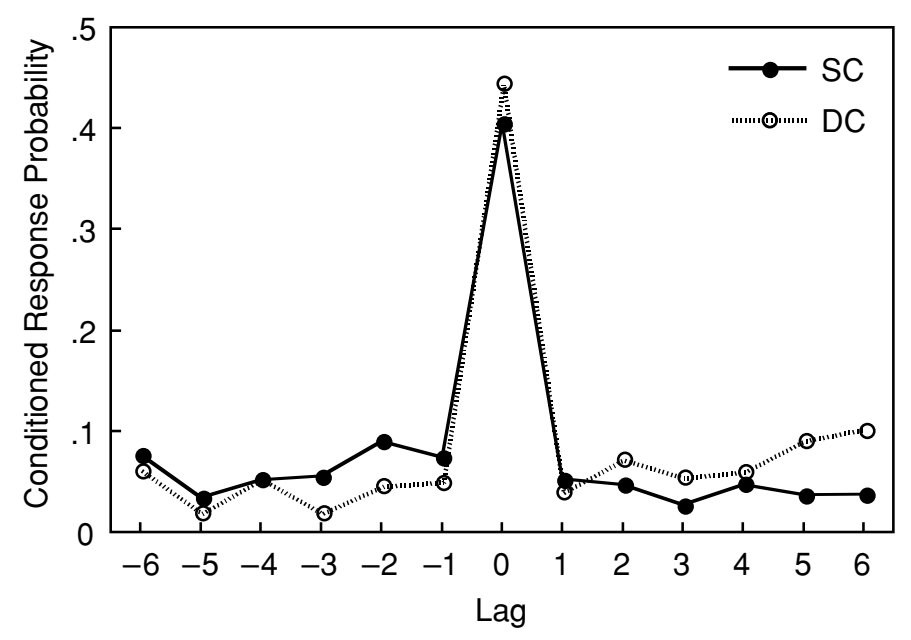

Figure 3. Conditional response probability modified for pair presentation as a function of context and serial position in Experiment 1. SC, same context; DC, different context.

in conflict with the ratio rule, which is the basis for most theories concerning the recency effect. However, before one draws a conclusion, the reliability of the present results should be examined, because a large number of previous studies have confirmed the ratio rule (e.g., Bjork, 2001; Crowder, 1993; Glenberg, 1984, 1987; Glenberg \& Swanson, 1986; Glenberg et al., 1983; Glenberg et al., 1980; Neath \& Crowder, 1990; Tan \& Ward, 2000).

The reinstated recency effect in the SC condition is formed mainly by the first two responses in free recall. Although the first response in the DC condition revealed a large primacy effect, this primacy effect was not reflected in the recall probability.

The conditional response probability showed an almost identical pattern in the SC and DC conditions: a profound peak at lag zero, and low plains at both sides of the peak. This result indicates that interitem associations were strongly formed within the item pairs but weakly between the pairs. In any case, the conditional response probability may not reflect the production mechanisms of the recency effect.

\section{EXPERIMENT 2}

The purpose of Experiment 2 was to replicate the result of Experiment 1 that a recency effect was observed when the original environmental context was reinstated for recall despite a nearly zero IPI/RI ratio. The methodology was nearly identical to that of Experiment 1, with only the following changes. First, the RI was shorter than that of Experiment 1 (10 min instead of $24 \mathrm{~h})$. Second, the way in which the participants spent time during the RI was changed from Experiment 1. In Experiment 1, participants returned to their own daily lives during the 24-h RI, and so their behavior was not controlled. In Experiment 2, every participant was required to engage in the same task throughout the 10-min RI in order to control participants' behavior. Third, three different contextual elements were used to manipulate the environmental context. Fourth, the participants were from a different university.

\section{Method}

Design. The design of Experiment 2 was identical to that of Experiment 1 .

Participants. The participants were 104 undergraduates enrolled in a Developmental Psychology course at Shizuoka Prefectural University, Shizuoka, Japan. They received extra course credit for participating. They were randomly assigned to the SC or DC condition, so that there were 52 participants in each condition.

Materials. The to-be-remembered list used in Experiment 2 was identical to that used in Experiment 1.

Context. A combination of three contextual elements (place, task, and background music) was systematically varied. The experimenter element was removed, and hence, the experimenter for the encoding and test session was the same for all conditions. Instead, a background music element was added to the contextual elements. In addition, the places used in Experiment 2 and the details of the task were different from those of Experiment 1.

For the place element, three places (A, B, and N) were selected to be as perceptually distinct as possible, each differing from the other in size, illumination, and objects and apparatus. Place A was a dimly lighted $200 \times 200 \mathrm{~cm}$ corner of a room, surrounded by one beige wall and three light gray screens. In Place A, there was a 17-in. computer screen, a mouse, a small table, and a chair. An experimenter instructed the participant from behind the participant's back, and then remained concealed behind the screens during the experimental session. Place B was a brightly lighted $550 \times 520 \mathrm{~cm}$ playroom for children. In Place B, there was a notebook computer with a 12in. computer screen and a mouse. In Place B, the experimenter and the participant sat facing each other across a $180 \times 90 \mathrm{~cm}$ table throughout the session. In front of the participant, there was a big window overlooking buildings and trees. A lot of toys were scattered about the space. Place $\mathrm{N}$ was a $410 \times 520 \mathrm{~cm}$ room with a table, two sofas, and two bookshelves. Places A, B, and $\mathrm{N}$ were on the same floor of the same building, though they were within a 1-min walk of each other. 


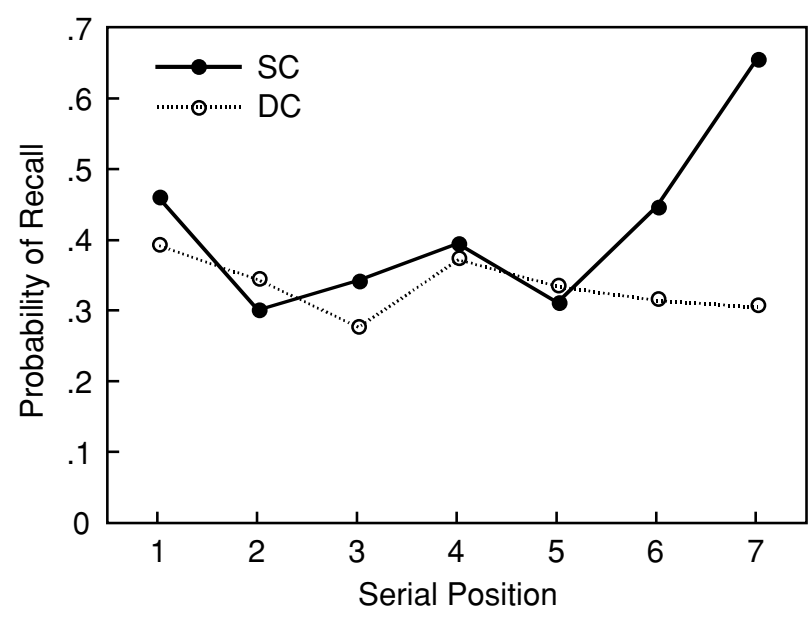

Figure 4. Serial position curves for same-context (SC) and different-context (DC) conditions in Experiment 2. Interpresentation interval $=\mathbf{3 0} \mathrm{sec} ;$ retention interval $=\mathbf{1 0} \mathbf{~ m i n}$.

During the calculation task, the participants in Experiment 2 use a mouse to press one of the numeric keys presented on the computer screen, whereas in Experiment 1 they pressed the numeric key on a keyboard by hand. The feedback tone for a correct response was a "Microsoft chime," and that for an incorrect response was a "Microsoft chord." The other task manipulation was identical to that of Experiment 1 .

The background music element was randomly selected from four instrumental music selections: "Tristeza" by Baden Powell, "Baby Elephant Walk" by the Henry Mancini Orchestra, "Song from Moulin Rouge" by the Mantovani Orchestra, and the theme of "Des Gens Sans Importance" from the original soundtrack.

Procedure. Participants were run individually for about $30 \mathrm{~min}$, which comprised a 10-min encoding session, a 10-min retention interval, and a 10-min test session. The SC participants attended both the encoding session and the test session in the same place with the same background music. In addition, at the beginning of the test session, the SC participants completed the same 30-sec calculation task as that imposed before and after the encoding of each word pair. The DC participants did the free recall test at a different place from that for the encoding session, with no background music, and they engaged in no task before the test. During the retention interval, both the SC and the DC participants were led to Place N, where they were required to solve word fragment completion problems. These problems were adopted from Fujita (1997). The time for solving the problems was about $8 \mathrm{~min}$, so that the retention interval would be about $10 \mathrm{~min}$. After the recall test, the participants completed an introspective questionnaire. Otherwise, the procedures were identical to those in Experiment 1.

\section{Results}

The data were scored and analyzed for both words from each pair. Figure 4 shows the probability of recall of individual words as a function of context and serial position. The serial-position curves in Figure 4 are almost identical to those in Figure 1, except that there are slightly higher prerecency portions for both the SC and the DC conditions. A $2 \times 7$ (context $\times$ serial position) ANOVA was computed. The main effects of context $[F(1,102)=13.35$, $\left.M S_{\mathrm{e}}=0.48, p<.001\right]$ and serial position $[F(6,612)=$
2.33, $\left.M S_{\mathrm{e}}=0.69, p<.05\right]$ were significant, and the interaction of these factors was also significant $[F(6,612)=$ $\left.2.78, M S_{\mathrm{e}}=0.69, p<.05\right]$. Simple context effects were analyzed for Serial Positions 1-7, because the interaction between serial position and context was significant. The context effect was not significant for Serial Positions 1-6 $[F \mathrm{~s}<1$ for Serial Positions $1-5$, and $F(1,714)=2.10$, $p>.10$ for Serial Position 6] but was significant for Serial Position $7[F(1,714)=15.88, p<.001]$.

Figure 5 shows serial position curves at Output Positions 1-5 for the SC (top panel) and DC (bottom panel) conditions in Experiment 2. At later output positions, there is insufficient data to plot reliable serial position curves. Figure 5 shows an almost identical pattern to Figure 2. The SC serial position curve (Figure 4) is characterized by the first two output positions, whereas the DC serial position curve (Figure 4) is not characterized by the responses of any output position.

Figure 6 shows the conditional response probabilities modified for pair presentations. The SC and DC curves show an almost identical pattern, which consists of a pro-
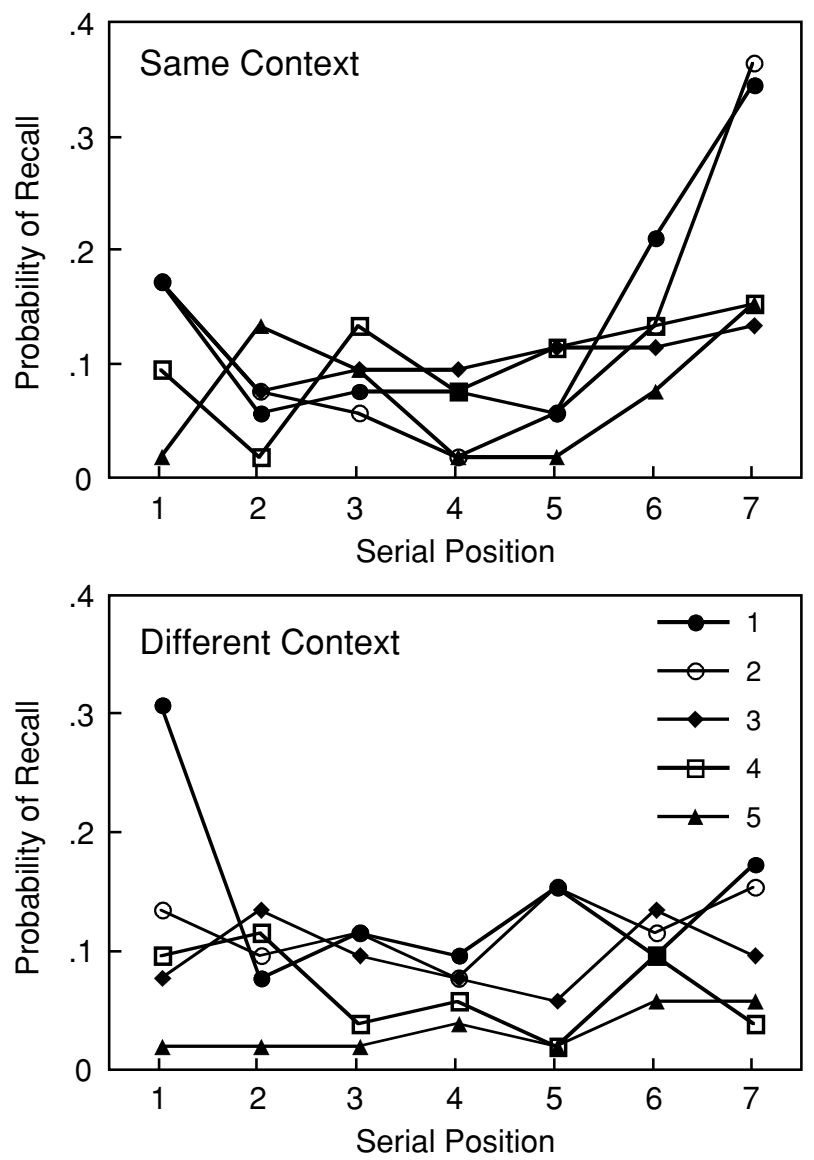

Figure 5. Serial position curves at Output Positions 1-5 for same-context (top panel) and different-context (bottom panel) conditions in Experiment 2. At later output positions, there was insufficient data to plot reliable serial position curves. 
found peak at lag zero and low plains on both sides of the peak.

\section{Discussion}

Experiment 2 successfully replicated the results of Experiment 1 . The results of Experiment 2 show patterns almost identical to those of Experiment 1 for all measures concerning the recency effect. First, the recall probability in the SC condition showed a clear recency effect, whereas the DC condition showed no recency effect. Second, the recency effect in the SC condition was mainly characterized by the first two responses in free recall. Third, the conditional response probability showed an almost identical pattern in the SC and DC conditions: a profound peak at lag zero, and low plains on both sides of the peak. Consequently, this successful replication of the results of Experiment 1 concerning the recency effect confirmed the reliability of the present findings.

In addition, there were also replicated patterns for the results in the prerecency portion. First, the SC condition showed a relatively small primacy effect whereas the DC condition showed almost no effect. The incidental learning and continuous distractor paradigms, used in the present experiments, have been reported to yield a relatively small primacy effect (Tan \& Ward, 2000). This should imply that the primacy portion of the list is processed less in the present experiments than in intentional learning and standard free recall paradigms. Second, the first response in free recall in the DC condition yielded a large primacy effect, but this primacy was not reflected in the recall probability for all the items; thus, the DC serial position curve showed no primacy effect. This may imply that a correlation between the recall probability and the response order may be found when the original environmental context helps recall, as for the first few responses in the SC condition. Without environmental context cues, the high probability of the first response may not be reflected in the recall probability.
Furthermore, the recall probabilities in Experiment 2 appeared to be slightly better than in Experiment 1 . The difference in the prerecency portion may have been caused simply by the RI. The total number of responses in free recall is inversely proportional to the RI. In the present experiments, the first few responses were mainly from the recency portion, and the following responses were from the prerecency portion. The number of responses following the first few responses largely determines the total number of responses. Thus, a decrease in the total number of responses, caused by the RI, necessarily causes a decrease in the number of the following responses, which are mainly from the prerecency portion. Thus, the recall probability of the prerecency portion should decrease with the length of the RI.

\section{GENERAL DISCUSSION}

In the present experiments, reinstatement of the environmental context present at encoding produced recency effects despite nearly zero IPI/RI ratios. This finding implies that the environmental context, as well as the time ratio, is involved in the production of the recency effect. Moreover, recency effects can be more comprehensively explained by environmental context dependent processes than by the ratio rule (e.g., Baddeley \& Hitch, 1993; Crowder, 1993; Glenberg et al., 1983; Glenberg et al., 1980). First, the present finding cannot be explained by the ratio rule but only by environmental context dependent processes. Furthermore, the IPI/RI ratio itself can be explained by the environmental context dependent processes. The IPI is proportional to the size of the environmental context surrounding the list-learning event, and the RI is proportional to the distance between the original learning and the testing events. Thus, the IPI/RI ratio should be proportional to the probability that the test is conducted within the original environmental context.

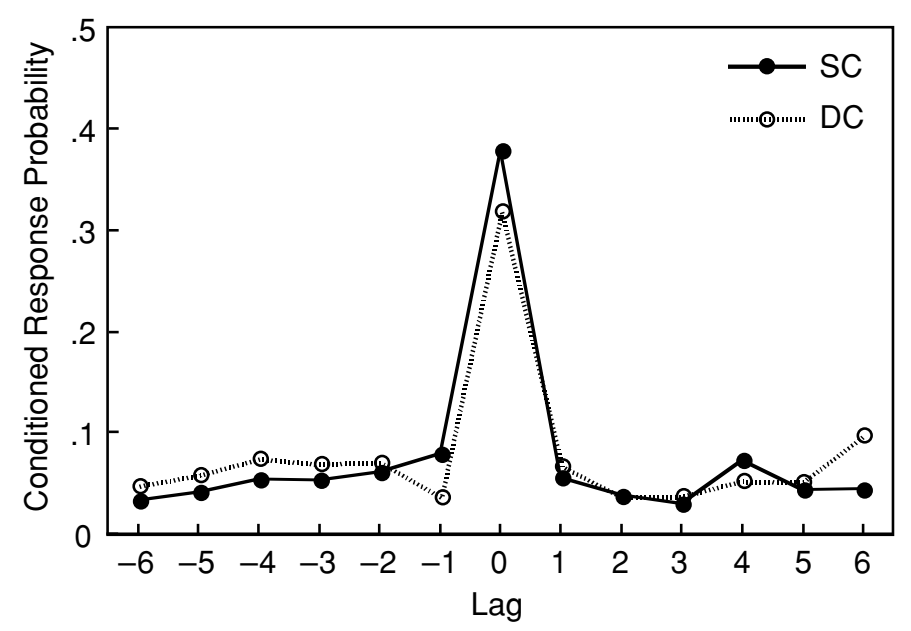

Figure 6. Conditional response probability modified for pair presentation as a function of context and serial position in Experiment 2. 
The present reinstated recency effect was mainly characterized by the first two responses in free recall. This finding is consistent with the previously reported finding that the recency effect in a continuous distractor paradigm is typically characterized by the first response (Howard \& Kahana, 1999; Isarida, 1989). In the present experiments, items within the pairs were strongly associated because they were presented one pair at a time. This strong within-pair association was supported by the results of the conditional response probability. Then, if items were presented one at a time, only the first response would form the recency effect. In addition, the first response in free recall is typically cued only by the environmental context, whereas the following responses are influenced not only by the context but also by interitem associations and output interference (Isarida, 1989, 2005). As a result, the environmental context dependent effects should appear especially in the first few responses, which constituted the recency effect in the present experiments.

In the present experiments, the recency portion of the list was much more salient than the primacy portion, although both the primacy and the recency portions should be typically salient in a standard free recall paradigm because of the end-of-the-list uniqueness. This is because the present experiments used incidental learning and continuous distractor paradigms, where the primacy portion should be less emphasized. Empirically, it has been found that the primacy effect is reduced in such paradigms (Tan \& Ward, 2000). Consequently, the recency portion was almost exclusively enhanced by the contextual cues. In contrast, the primacy portion should be emphasized when learners encode items with cumulative rehearsals (Tan \& Ward, 2000). Furthermore, reinstatement of the original environmental context has been found to influence the cumulative rehearsal effect on free recall especially for the primacy portion but not for the recency portion of the list (Isarida, 1992). Possibly, the reinstated environmental context should enhance recall of the salient portion of the list, regardless of whether the portion is recency or primacy. In summary, the salient portion is almost always recalled first, and the first response is the most sensitive to the environmental context cue as described above.

The environmental context dependent processes may not influence recency effects when the environmental context cue is associated with so many items as to cause cue overload. In most experiments, both the initial study and the later testing of recall have been completed within one experimental session and hence within one environmental context. Even if participants left the laboratory during a long RI, they almost always returned to the same laboratory and received the memory test from the same experimenter. As a result, the original context was reinstated at the time of testing. However, the presence of the original environmental context produced no recency effects with nearly zero IPI/RI ratios, although in the present experiments, reinstatement of the original environmental context produced recency effects despite a nearly zero ratio. In previous experiments (e.g., Bjork \& Whitten, 1974), the environmental context could not aid the retrieval of items despite the presence of the original context, because the number of items associated with only one environmental context was too large. In most experiments, more than a hundred items were presented within the session. Thus, environmental context would be a poor cue for retrieval of individual items because of cue overload (Watkins \& Watkins, 1975).

Tzeng (1973) found a recency effect despite a low IPI/ $\mathrm{RI}$ ratio using a relatively small number of items, as also was found in the present experiments. Tzeng's participants received four lists of 10 items with a 20-sec IPI and a 20sec RI, and a free recall test of the items after each RI. Two minutes after the last recall period, the participants were required to recall all of the items again (final free recall). The serial position curve within the lists in the final free recall showed a clear recency effect, although the IPI/RI ratio (20-sec IPI to a more than 2-min RI) was small. In comparison, Bjork and Whitten's (1974) Experiments 2 and 3 showed no recency effect in final free recall with a 20-sec IPI and a 2- to 3-min RI. The total number of items used in their experiments was 160 (eight lists of 10 pairs of items), and hence the cue strength of the environmental context was weak. In conclusion, the environmental context plays a role in the production mechanism of the recency effect. Nonetheless, little research has demonstrated this effect of environmental context, because the large number of items used in most experiments has led to cue overload.

Memory experiments typically use more than a hundred items; as a result, environmental context may not have aided retrieval of the items because of cue overload. Thus, researchers may have missed the fact that a variety of episodic memory phenomena, including the recency effect, are influenced by the environmental context. In fact, it has been found that the production of some episodic memory phenomena, such as the study time effect, the rehearsal effect, and the spacing effect of repetition in free recall are influenced by the reinstatement of the original environmental context with a small number of items (Isarida, 1992, 2005; Isarida \& Morii, 1986). One list of items is sufficient for the detection of a recency effect. Although using a number of lists, or using more than a hundred items, makes the recency effect data more reliable, it also leads to cue overload for environmental context effects. The data from only one list with a small number of items can be reliable with increased numbers of participants and with replication. Thus, it should be reconsidered for use in experimental situations where environmental context could not otherwise aid retrieval of items because of cue overload.

It should be noted that the present environmental context explanation may not apply to the studies in which items have been encoded across several experimental sessions (Glenberg et al., 1983, Experiment 5) or across several daily events (Baddeley \& Hitch, 1977) separated by one to several days or more. In these studies, the list-learning context would not be reinstated, even if each encoding session and test session were conducted in the same environmental context. This is because each environmental 
context does not surround the total list-learning event and hence cannot reinstate the whole list-learning context but only each separate encoding context.

Finally, the present experiments have demonstrated that reinstatement of the original environmental context produces a recency effect even when no recency effect is predicted according to the ratio rule. In addition, this reinstated recency effect is characterized by the first few responses in free recall. The next issue to be examined is whether or not a recency effect is eliminated by changing the environmental context present at encoding even when a significant recency effect is predicted according to the ratio rule. If the recency effect is eliminated in such an experiment, then recency effects will be shown to have been determined not by the IPI/RI ratio but by the environmental context. In any case, further research is needed.

\section{REFERENCES}

Baddeley, A. D., \& Hitch, G. (1977). Recency reexamined. In S. Dornic (Ed.), Attention and performance VI (pp. 647-667). HIllsdale, NJ: Erlbaum.

BadDEley, A. D., \& Hitch, G. (1993). The recency effect: Implicit learning with explicit retrieval? Memory \& Cognition, 21, 146-155.

BJORK, R. A. (2001). Recency and recovery in human memory. In H. L. Roediger III, J. S. Nairne, I. Neath, \& A. M. Surprenant (Eds.), The nature of remembering: Essays in honor of Robert G. Crowder (pp. 211232). Washington, DC: American Psychological Association.

BJork, R. A., \& Whitten, W. B. (1974). Recency-sensitive retrieval processes in long-term free recall. Cognitive Psychology, 6, 173-189.

Blaney, P. H. (1986). Affect and memory: A review. Psychological Bulletin, 99, 229-246.

CRAIK, F. I. M. (1970). The fate of primary memory items in free recall. Journal of Verbal Learning \& Verbal Behavior, 9, 143-148.

Crowder, R. G. (1976). Principles of learning and memory. Hillsdale, NJ: Erlbaum.

Crowder, R. G. (1993). Short-term memory: Where do we stand? Memory \& Cognition, 21, 142-145.

Davelaar, E. J., Goshen-Gottstein, Y., Ashkenazi, A., HaarMANN, H. J., \& UsHER, M. (2005). The demise of short-term memory revisited: Empirical and computational investigations of recency effects. Psychological Review, 112, 3-42.

EICH, J. E. (1980). The cue-dependent nature of state-dependent retrieval. Memory \& Cognition, 8, 157-173.

Fusita, T. (1997). Construction of word-fragment completion task on implicit memory research [in Japanese]. Research Bulletin of Koka Women's College, 35, 111-126.

Glanzer, M., \& Cunitz, A. R. (1966). Two storage mechanisms in free recall. Journal of Verbal Learning \& Verbal Behavior, 5, 351-360.

GLENBERG, A. M. (1984). A retrieval account of the long-term modality effect. Journal of Experimental Psychology: Learning, Memory, \& Cognition, 10, 16-31.

GlenberG, A. M. (1987). Temporal context and recency. In D. S. Gorfein \& R. R. Hoffman (Eds.), Memory and learning: The Ebbinghaus centennial conference (pp. 173-190). Hillsdale, NJ: Erlbaum.

Glenberg, A. M., Bradley, M. M., Kraus, T. A., \& RenZaglia, G. J. (1983). Studies of the long-term recency effect: Support for a contextually guided retrieval hypothesis. Journal of Experimental Psychology: Learning, Memory, \& Cognition, 9, 231-255.
Glenberg, A. M., Bradley, M. M., Stevenson, J. A., Kraus, T. A., TKachuK, M. J., GretZ, A. L., et AL. (1980). A two-process account of long-term serial position effects. Journal of Experimental Psychology: Human Learning \& Memory, 6, 355-369.

GlenberG, A. M., \& Swanson, N. C. (1986). A temporal distinctiveness theory of recency and modality effects. Journal of Experimental Psychology: Learning, Memory, \& Cognition, 12, 3-15.

Howard, M. W., \& KaHANA, M. J. (1999). Contextual variability and serial position effects in free recall. Journal of Experimental Psychology: Learning, Memory, \& Cognition, 25, 923-941.

IsARIDA, T. (1989). Role of output interference on long-term recency effects. Japanese Journal of Psychology, 60, 24-30.

IsARIDA, T. (1992). Influences of environmental-context changes on rehearsal effects in episodic memory. Japanese Journal of Psychology, 63, 262-268.

IsARIDA, T. (2005). Study-time effect on free recall within and out of context. Memory, 13, 785-795.

IsARIDA, T., \& IsARIDA, T. K. (2004). Effects of environmental context manipulated by the combination of place and task on free recall. Memory, 12, 376-384.

IsARIDA, T., \& MoRII, Y. (1986). Contextual dependence of the spacing effect in free recall. Japanese Journal of Psychology, 57, 20-26.

Kahana, M. J. (1996). Associative retrieval processes in free recall. Memory \& Cognition, 24, 103-109.

Koppenaal, L., \& Glanzer, M. (1990). An examination of the continuous distractor task and the "long-term recency effect." Memory \& Cognition, 18, 183-195.

Murnane, K., \& Phelps, M. P. (1993). A global activation approach to the effect of changes in environmental context on recognition. Journal of Experimental Psychology: Learning, Memory, \& Cognition, 19, 882-894.

NeATH, I. (1993). Contextual and distinctive processes and the serial position function. Journal of Memory \& Language, 32, 820-840.

Neath, I., \& Crowder, R. G. (1990). Schedules of presentation and temporal distinctiveness in human memory. Journal of Experimental Psychology: Learning, Memory, \& Cognition, 16, 316-327.

Ogawa, T., \& Inamura, Y. (1974). An analysis of word attributes imagery, concreteness, meaningfulness and ease of learning for Japanese nouns. Japanese Journal of Psychology, 44, 317-327.

RAND, G., \& WAPNER, S. (1967). Postural status as a factor in memory. Journal of Verbal Learning \& Verbal Behavior, 6, 268-271.

Sмith, S. M. (1988). Environmental context-dependent memory. In G. M. Davis \& D. M. Thomson (Eds.), Memory in context: Context in memory (pp. 13-33). New York: Wiley.

Smith, S. M., \& Vela, E. (2001). Environmental context-dependent memory: A review and meta-analysis. Psychonomic Bulletin \& Review, 8, 203-220.

TAN, L., \& WARD, G. (2000). A recency-based account of the primacy effect in free recall. Journal of Experimental Psychology: Learning, Memory, \& Cognition, 26, 1589-1625.

Thapar, A., \& GreEne, R. L. (1993). Evidence against a short-term store account of long-term recency effects. Memory \& Cognition, 21, 329-337.

TzENG, O. J. L. (1973). Positive recency in a delayed free recall. Journal of Verbal Learning \& Verbal Behavior, 12, 436-439.

WATKINs, O. C., \& WaTKINS, M. J. (1975). Buildup of proactive inhibition as a cue-overload effect. Journal of Experimental Psychology, Human Learning \& Memory, 1, 442-452.

(Manuscript received September 3, 2004; revision accepted for publication May 18,2005 .) 